\title{
Discussion and Analysis on Ecological Packaging Design in Influence of Crossover Concept
}

\author{
Huanan Shang \\ School of Art and Design \\ Huanghe Science and Technology College \\ Zhengzhou, China 450046
}

\begin{abstract}
A new "Crossover" trend has emerged in the previous design types which are distinctly separated from other sectors, and innovation is its essence. Under such context, ecological packaging indicates a character of cross-discipline with great classical significance. This paper has paid attention to describe that ecological packaging is a systematic engineering, and a completed crossover design trend and a diversified expression method; and has stressed that ecological packaging indicates a multidimensional development trend in terms of social demand, diversification and personalization; besides, this paper has laid emphasis on multi-level and crossover analysis against ecological packaging, and has explored and researched on its crossover characteristics and depth.
\end{abstract}

Keywords-ecological packaging; crossover; demand experience; emotional appeal; integration

\section{INTRODUCTION}

As for a designer, "crossing" contained in the Crossover renders him a great creation inspiration to obtain a brand new design concept. As the essence for design is innovation, under the background of information era, the world "Crossover" appears on fashion magazines and websites frequently. A new "Crossover" trend emerges among the previous design types that are distinctly separated form other sectors. The basic meaning of Crossover is cross-border cooperation, referring to the cooperation in different fields, and even representing a new prominent fashion attitude and life style. [1]

As a brand new trend of thought for design, ecological design displays a more and more thriving vitality under the background of green revolution. Ecological packaging displays its influence that shall not be ignored in this Crossover trend with significance beyond function.

\section{BRAND NEW DESIGN APPEAL OF CROSSOVER ESTABLISHMENT}

Different design style and design thinking bring about the spark for inspiration from different fields within the design fields at present times. The collision of those elements has brought about new flavor of "mash up" for the fashion industry, and has aroused new thinking among industry field. "Crossover" is becoming a general action strategy no matter for the artists or designers. It seems to be a trend, many scholars has defined "Crossover" as a new concept simultaneously.

As one cultural and artistic activity, packaging is of strong sense of history. Meanwhile, it has deeply reflected the mutual influence between the cultural background at that times and recognition of people's consumption. Ecological packaging is a product of people's thinking and selfreflection in the green revolutions. Under such context, ecological packaging displays the disciplinary crossover with great classical significance. Facing the sophisticated trend of crossover design and diversified expression methods, ecological has indicated a more and more specific diversified development trend in terms of social demands, diversification and personalization.

Ecological packaging is a dynamic concept, and we should learn about its connotation by putting it into a dynamic, constantly evolving, and updating marketing environment. Modern conventional packaging design shall tackle with such basic problems as protection, transportation and storage of the products, meanwhile, such propaganda issues as product quality and corporate image shall be expressed as well. As for ecological packaging, in addition to settle the above mentioned problems, what is more important is how to resolve the problems as reducing pressure to the environment, protecting ecological balance, taking full use of recycling and reusing. Therefore, it is a comparatively systematic subject area of vague definition, a diversified subject theory integrating materials science, value engineering, sociology, psychology, marketing, technological aesthetics and ergonomics. Along with the globalization of consumption mode and development of green revolutions, the influence of ecological packaging has developed unprecedentedly in terms of depth and width "Fig. 1", "Fig. 2". [2] 


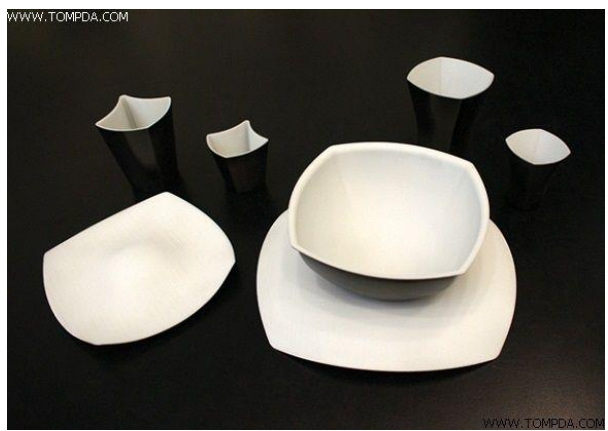

Fig. 1. Use of corn starch produced by fast-food Tableware

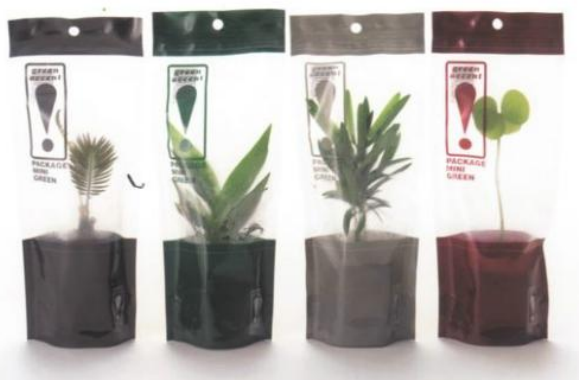

Fig. 2. Use of biodegradable plastics production plant sales package

\section{SPECIAL DESIGN VocABULARY OF ECOLOGICAL PACKAGING}

In March 1980, the United Nations has made an appeal globally that "The research on basic relation of nature, ecology, economy, and that in the process of using natural resources shall be conducted to ensure global sustainable development." The UN has set up World Committee of Environment and Development (WECD) in November 1983. And in 1987, after 4 years research, the Committee has fully proved and presented the report of Our Common Future, putting forward the sustainable development mode, making a comprehensive systemic evaluation of the problems existing in human economic development and environmental protection. [3]

As a global explicit philosophy, ecology stresses the balance and intergrowth among human, nature and environment. Ecological design main displays the following characteristics as one important branch of ecology: Firstly, pursuing to return to the original nature, and claiming to be the theory and practice for integrating and intergrowth of design and nature; secondly, designing the products of diversification and combination using diversified design thinking to realize sustainable development of design; thirdly, transforming the simple production mode of production, circulation, consumption and abandonment into a recycling and reusing production mode; and forth, the concept of finished products design has been gradually eliminated, while commodities and their service environment has always been in the status of change and growth, and the design industry is in a status of growing, updating and perfecting. [4]

Packaging is to meet our demand for protecting products, and a core system to maintain our life style in current design field. However, the dilemma faced by the design field is: obtaining "beautiful garbage" using large amount of money. Inappropriate business behavior has cause great damage to the environment, and those packages are regarded as a chief offender for the deteriorating living environment. While ecological packaging is a self-reflection of modern design value in terms of generality, equality and standardization, which pays attention to the crossover thinking and positive significance between consumption custom and social value orientation, personal and regional culture, material and spiritual level. Specific design expression mainly displays the following characteristics:

\section{A. High Technology in this Design}

Ecology high technology design constantly updates their design knowledge, skills and concept within the design of ecological packaging. Material is the foundation for ecological packaging, while science and safe are the basis for consideration. The development and application of new materials are benefit from the rapidly developing modern science and technology. For example, degradable plastic is regarded as one of ecological packaging materials with the highest development prospect by the educational circles. Such material, which can be degraded and restored in natural environment and return to the ecological environment as non-toxic material, is a hotspot of material research and development. At present, in the ecological packaging field, degradable plastic has been widely used in food package, turnover box, grocery bag and outer package for various products. Edible packaging materials have been widely used in recent years as well, including starch, protein, plant fiber and other natural -occurring substances, which are the green packaging material with highest development prospect. Through blending and modifying those natural materials, they can meet the requirements for food packaging very well, especially the packaging for large quantity of fast food. There are also plenty of high-tech green packaging materials, such as, chitin biological packaging material, natural plant fiber packaging material, and nanometer materials etc.

The development of technology has added wings to ecological packaging for its ideal, and such multi-level Crossover design has rendered the consumers a brand new consumption experience. The significance beyond function has been accomplished through such ecological packaging.

\section{B. Design Moves toward "Greenization"}

Design is an activity of production and consumption in terms of its essence, and it is a behavioral process of production and consumption with purpose and predictability to meet people's certain consumption needs.

As for the designer, he shall transplant the ecological design system into the internal design process, and update the concept actively, master the technology, grasp commodity attribute accurately in the process of design, enable the ecological package obtain harmony with the surroundings in terms of vision, and establish consumption emotions in the process of consumers' using of it. "Fig. 3", "Fig. 4" 


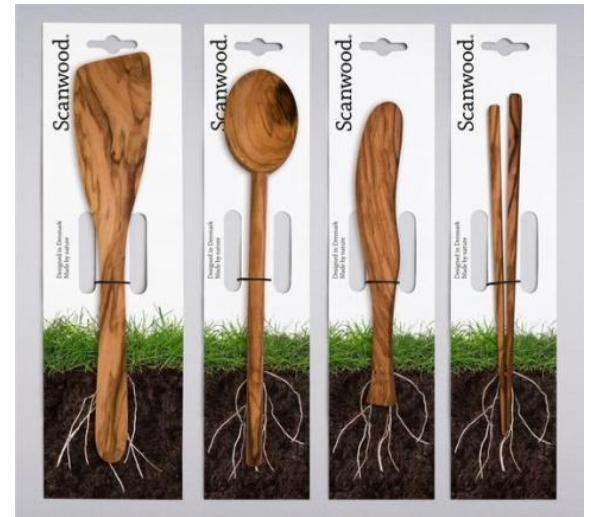

Fig. 3. Cutlery packaging

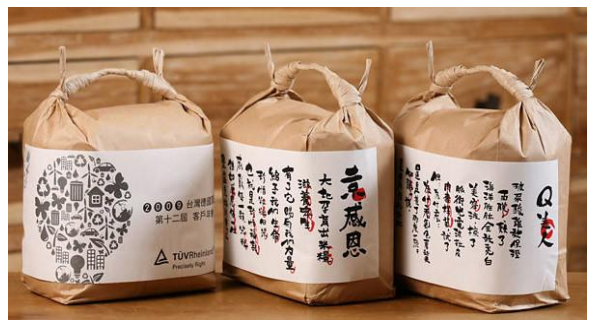

Fig. 4. Taiwan's food packaging

\section{Tendency of Digitalization and Intellectualization}

Ecological packaging may calculate accurately the energy consumption and ecology effect in the protocol stage via the technology of digital virtual reality, reducing the consumption of non-recyclable energy and relevant mechanical consumption to the maximum level, and realizing the objective of reducing carbon emission. Ecological packaging has combined artificial intelligence and computer intelligence to design out an adjustable product adapting to out environment, thus to create the efficient, comfortable and energy saving packaging products, enabling the ecological packaging itself to become an ecological system with reaction capacity and self-regulation function. "Fig. 5", "Fig. 6"

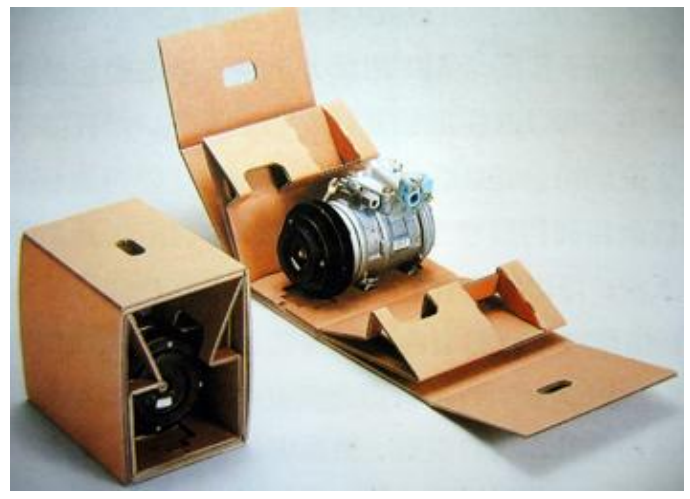

Fig. 5. Cushioning package of corrugated paper production

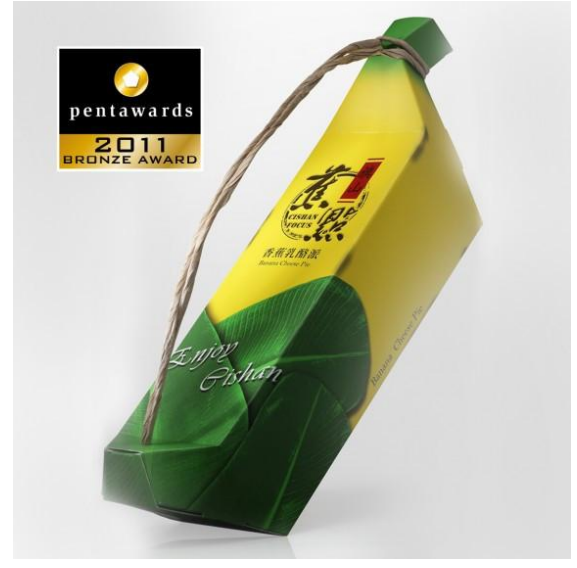

Fig. 6. Bionic form of food packaging

\section{Multidimensional SEMANTIC EXPRESSION OF ECOLOGICAL PACKAGING CROSSOVER}

\section{A. Function Crossover of Ecological Packaging}

A good packaging design shall meet the basic function first of all, requiring the package has a certain structure. In order to become a packaging product that meets environmental requirement, ecological packaging shall design in-depth in terms of function. Realize packaging function using minimum materials; take full consideration of material source and reduce of categories of the materials used; take consideration of operation mode of package and its disposing means after use; the operation shall be easy for operators; and the production process of the package shall meet the environmental requirement, for example, adopt such technology as soybean and ink. The character of "ecology" shall be fully displayed in visual communication, and the product identification in the market shall be enhanced, enabling consumers to fully experience the communication of sensibility and information in the purchasing process.

\section{B. Design Convince-Marketing Crossover}

Packaging design tends to pursue humanization increasingly, and to realize balance between human and object with efforts, while paying attention to the affinity between model and visual communication elements and the consumers, enabling consumers obtain the comfortable sensation of victory and psychological pleasant feeling, [5] which is the developing trend of modern packaging. Maslow's "Demand Theory" reminds designers to pay more attention on inner emotional demand, while laying emphasis on consumers' basic physical demand, namely to take consumers' aesthetic emotion into consideration in order to stimulate emotional consumption.

Ecological packaging is of specific selling point itself in the marketing process. Consumers' sense of responsibility in terms of using, recycling and discarding shall be intensified constantly, establishing a friendly interactive consumption experience between product and consumer. For example, the used packaging box can be recycled as flower pot. Many of 
Japanese public washrooms are posting with such slogan "The paper you are using is recycled from milk cartons". Make consumers enjoy the pleasure through direct or indirect involvement, enabling them experience profoundly the unique charming and significance of ecological packaging "Fig. 7", "Fig. 8".
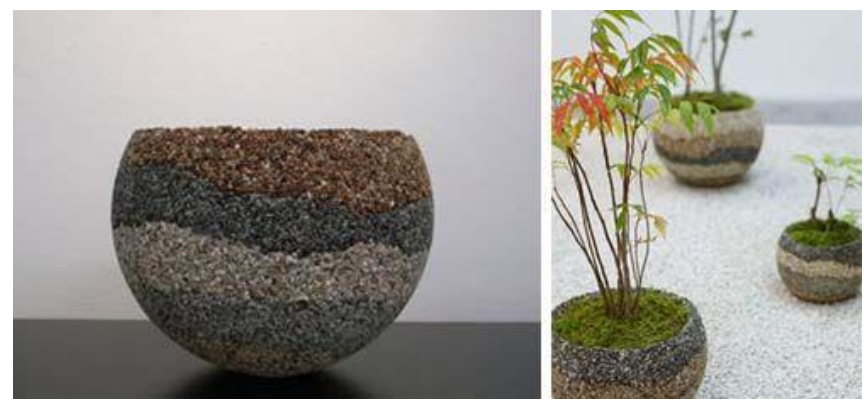

Fig. 7. Pots made of recyclable materials

\section{無印良品的三个理念}
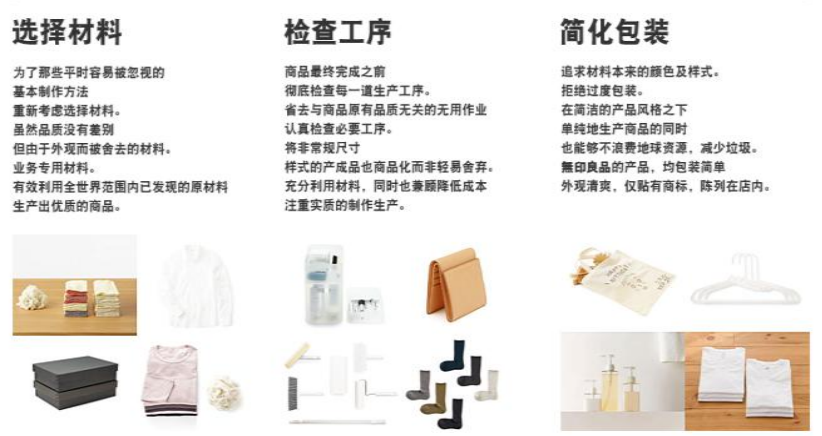

Fig. 8. The MUJI three design concept

\section{Crossover Integration of Design Concept}

Human are the products of nature. And ecological packaging stresses that under such condition human follow the ecological law and social aesthetics rule, the artifacts using scientific strategy and means shall meet natural and humanistic characteristics, enabling people the permanent material and spiritual enjoyment beyond visual effect. [6]

The theory of ecology has only developed for 100 years recently in western countries, and more often it is a delayed reflection on ecological crisis. In Chinese traditional conception of nature, "unity of nature and human" is the most genuine ethical principle. And the core connotation of "unity of nature and human" is the harmony of human and nature. [7] Lao Tzu describes that all the things on earth are generated form Tao, and the essence of Tao is of nature and certain rules. Under the circumstances that globalization and internationalism is being the main current of design, the development of China's ecological packaging shall take "Tao" of "unity of nature and human" as its guiding thought. In facing of serious ecological crisis, designers shall change their thinking mode to respect value of nature while acknowledging value of human, advocating and executing the relation of equality between nature and human on the level of human and nature's production and development. [8]

\section{CONCLUSION}

The concept of ecological packaging may be just a label; actually, the real contents of it are crossover and integration of all the humanistic knowledge relevant to design. Ecological packaging has broken our original mindset using its unique manner with inclusive development, rendering itself the diversified cross-disciplinary. The connotation of ecological packaging is constantly enriching with the influence of "Crossover", bring about the brand new design with strong impact, which is the developing trend in future.

\section{REFERENCES}

[1] Feng Yu. Cross-border cooperation--- Continuity of design life and design variability of the descent[J]Meiyuan,2008, 6:90-92.

[2] Ma Lei. Discussion on Sustainable Packaging Design[J]. Packaging Engineering, 2011, 32 (4) :77-80.

[3] Wang An-xia.The visual design of the packaging image.Nanjing: Southeast University Press, 2006

[4] Liu Xiao-tao. Eco-design[M]. Shandong Art Publishing House : Jinan.2006

[5] Li Bin-bin. Design Psychology[M].Beijing. China Light Industry Press, 2001

[6] Jin Zheng-ping. The dimension of the green packaging design[J]. Packing journal, 2010, $7: 61-62$

[7] Li Jian-qiang. Nature-based design from the "Green Design".[J] Art Panorama, 2007, 4:48-51

[8] Jiang Ke -ke. Barrier-free Product Pesign for Old People[J]. Packaging Engineering, 2006, 27(6): 22-25. 